\title{
Passive smoking and its impact on employers and employees in Hong Kong
}

\author{
S M McGhee, A J Hedley, L M Ho
}

Occup Environ Med 2002;59:842-846

See end of article for authors' affiliations

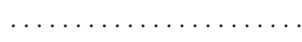

Correspondence to: Dr S M McGhee,

Department of Community Medicine, University of Hong Kong, 5th Floor,

University of Hong Kong

Medical Centre, 21

Sassoon Road, Hong

Kong;

smmcghee@hkucc.hku.hk

Accepted 10 April 2002

\begin{abstract}
Aims: To estimate the prevalence of passive smoking at work in the whole workforce in Hong Kong (population 6.8 million), the characteristics of the passive smokers, any extra use of health care among passive smokers, and who pays for that health care.

Methods: A random sample of 14325 households was contacted by telephone; 6186 responding adults who worked full time were asked about their employment, their most recent use of health care and the cost of that care, their medical benefits, and their exposure to secondhand smoke in the workplace. After weighting the sample for sex, age, household size, and income, 4739 subjects were included in the analysis.

Results: Of 1961 full time workers who did not smoke, $47.5 \%$ were exposed to secondhand smoke in the workplace compared with only $26 \%$ exposed at home. Exposure at work was associated with being younger, male, married, less educated, and having a lower income. Those exposed at work were $37 \%$ more likely to report having visited a doctor for a respiratory illness in the previous 14 days. Employers were paying $28 \%$ of the cost of these visits, the government paid $8 \%$, and the individuals paid $63 \%$. If extrapolated to the 3 million workers in the Hong Kong population, employers would pay just over US $\$ 9$ million per year, while the affected workers would pay around US $\$ 20$ million.

Conclusion: As well as the costs of active smoking, the cost of extra health care utilisation associated with passive smoking is an additional cost being paid by those employers who have not established smoke free workplaces and by their employees.
\end{abstract}

S econdhand tobacco smoke is classified by the International Agency for Research on Cancer as a group l carcinogen and there is a growing amount of epidemiological evidence that exposure to secondhand smoke has effects on health similar in nature, although less in extent, to those of active smoking. We now know that secondhand smoke causes lung cancer and respiratory illness as well as more minor respiratory symptoms and annoyance in non-smokers. ${ }^{1}$ Increasing evidence also points to a link with heart disease. ${ }^{2}$

The American Cancer Society's data on regulations governing smoking throughout the world indicate that $56 \%$ of the countries and territories in the WHO region of the Americas and $71 \%$ in the European region have some sort of regulation governing smoking in the workplace. ${ }^{3}$ In both the Americas and Europe, around $50 \%$ of these regulations are complete bans, the most effective means of reducing the concentration of secondhand smoke in the workplace. ${ }^{4}$ Nonetheless, Kauppinen et al estimate that 7.5 million European workers are exposed to secondhand smoke for at least $75 \%$ of their working time, the second most common exposure to group 1 carcinogens in the workplace after solar radiation. ${ }^{5}$ In the USA, the Centre for Disease Control's Third National Health and Nutrition Examination between 1988 and 1991 showed that exposure to secondhand smoke was widespread and that workplaces were making an important contribution to this exposure. ${ }^{6}$ The 1988 National Health Interview Study estimated that $37 \%$ of workers worked in places that permitted smoking and that $59 \%$ of these experienced discomfort. ${ }^{7}$ However, in California, self reported exposure to secondhand smoke at work declined between 1990 and 1993, from 29\% to $22 \%$, with the trend towards smoke free workplaces. ${ }^{8}$ In South East Asia and the Western Pacific, the situation is worse than in the USA. Around 50\% of the countries in the WHO South East Asian region and 63\% of those in the Western Pacific region report that they have some regulations or laws covering workplace smoking, but only $20 \%$ and $32 \%$ of these respectively are complete bans on smoking, ${ }^{3}$ the rest being restrictions or voluntary arrangements with probably little overall impact. The WHO Western Pacific Regional Office reports that $52 \%$ of the population in Pnom Penh, Cambodia, is exposed to secondhand smoke. ${ }^{9}$ Hong Kong has some smoke free workplace policies, but these only apply to government buildings, tertiary educational institutions, transport, banks, shopping malls, and indoor places of entertainment. A survey of the police force found that $80 \%$ of those who had never smoked were exposed to tobacco smoke at work. ${ }^{10}$

Active smokers take more time off work and use more health care services than non-smokers do ${ }^{11}$; a study in Hong Kong showed a similar, though smaller, association between use of health services or time off work and passive smoking. ${ }^{12}$ White et al estimated that passive smokers in San Diego lost 1.2 extra days from work because of respiratory problems, ${ }^{13}$ while Mannino et al found an excess of days of restricted activity, bed confinement, and work absence in passive smokers. ${ }^{14}$ Smoking at work and in public places results in financial costs. The US Environmental Protection Agency ${ }^{15}$ estimated that banning smoking in all non-residential indoor environments would produce overall net benefits of \$US 39-72 billion; they did not, however, identify on whom the gain would fall or who is currently paying these costs.

Asian countries currently have high and growing rates of smoking, ${ }^{9}$ and with a lower extent of restrictions, may stand to gain even more from prevention of smoking at work, in terms of preventing health impairment and monetary loss. We wished, in this study, to identify the exposure to secondhand smoke in a whole working population in Asia and to determine the characteristics of those exposed. We also hoped to identify any extra health care use, costs of such health care use, and whether employers were paying any of the cost.

\section{METHODS}

Between January and March 1998, a telephone survey was conducted on a random sample of 14325 households in Hong Kong, resulting in 6186 successful interviews. The sampling 
frame was all Hong Kong residents who live in a household with a telephone; random telephone numbers were selected from residential telephone directories and additional numbers generated by the computer to capture unlisted numbers. Five attempts were made to obtain a response. Of the households initially reluctant to be interviewed (53\%), 606 were called back and 142 successful interviews were carried out. These 142 differed from the other respondents only in being slightly older (mean age 43 years versus 38 years). Non-contact bias was examined by comparing the respondents contacted at the first attempt $(n=5050)$ with those contacted after the fifth attempt $(n=42)$. The later respondents were more likely to be male $(71 \%$ versus $45 \%)$ and to be in a smaller household (mean number of household members 3.02 versus 3.94). Reliability was tested by repeat interviews of 104 people; $89 \%$ of these matched on all variables. Comparison with census data showed that we had under sampled smaller households, with $5.3 \%$ of the sample but $14.9 \%$ of the population being in single person households. The data were subsequently weighted for sex, age, household size, and household income to better represent the population, resulting in 4739 subjects with full data.

The self reported data included demographic data, working status, type of occupation and industry, household income, number of household members, health status, use of ambulatory health care services in the past 14 days, reason for the most recent consultation, type of medical benefits, smoking habits, and exposure to other people's smoke at work and at home. Smoking habits were determined by asking "Do you currently smoke?"; non-smokers were those who replied "no"- this group thus includes never and former smokers. The question which measured passive smoking exposure at work was "In the place you work (in the same office, shop floor, or about 10 feet around you) does anyone smoke (including co-workers and other people)? If yes, how many (not including you)?". Exposure at home was asked by "In the past one month, among those who lived with you in the same household or unit, did anyone smoke in the household or unit? If yes, how many (not including you)?". Health status was rated by the respondent on a five point scale; poor health was defined as a rating of the 4th or 5th level. Respondents were also asked about the existence of chronic disease and its nature. The reasons for the use of ambulatory health care were recorded in categories including the specified chronic disease, cold/flu/fever, other health problem, check up, for medicine, or for preventive services. The cold, flu, or fever category was separately specified in order to allow the analyses described in this paper. The occupations and industries worked in were classified according to the government Census and Statistics Department's classification. ${ }^{16}$ Per capita household income was derived by dividing the declared household income by the number of household members.

Association of exposure to passive smoking with consultation for cold, flu, or fever was examined using multiple logistic regression. Factors considered to have a possible independent effect on utilisation were included as covariates. Association with consultation for any reason and for any reason except preventive services was also examined.

To compare the prevalence of smoking in the workforce in each industry with the exposure to passive smoking by the non-smokers, we ranked the industries for each prevalence and tested the association using Kendall's tau.

To identify whether exposure to passive smoking was associated with extra consultation costs, we calculated the population attributable risk (PAR) of a consultation for a cold, flu, or fever given exposure to secondhand smoke, for all nonsmoking full time workers. We carried out this calculation for groups stratified by the industry worked in. Using these industry specific PARs and the prevalence of consultation for cold, flu, or fever in that industrial group, we calculated the mean number of extra visits associated with exposure for each group. This was combined with the mean reported costs of a consultation in that industrial group. The costs were summed across the groups and aggregated up to a year by multiplying by 26 , since the consultation rate had been estimated for the previous 14 day period only.

From the survey, we know whether the respondents have medical benefits, how much they paid for the consultation, and whether and how much they were reimbursed. Copayments for public services, non-reimbursed costs of private services, and those costs covered by insurance were designated as private costs; those covered or reimbursed by the employer were designated as employer costs. The cost of attendance at a public clinic was conservatively estimated as US\$19.2 (HK\$150) and the balance after deduction of the small co-payment was assigned to government costs. Those respondents who failed to provide some of the detailed data on benefits or amounts paid for health care did not differ in demographics, employment, or health status from those who provided complete data; we have assumed that the corresponding group mean costs also apply to them. We used the 95\% confidence limits for the odds ratios to calculate lower and upper bounds for the extra visits and costs.

To extrapolate results to the whole working population of Hong Kong, we used the industrial group specific sample data and actual numbers working in that industry according to the latest government census data. ${ }^{16}$ All analyses were done using Stata version 6.0.

\section{RESULTS}

Of the 4739 adults (over 15 years old) in the weighted sample, $56.4 \%$ work full time; of the full time workers, 1961 (73.4\%) do not smoke, but $47.5 \%$ of these non-smoking workers are exposed to secondhand smoke in their workplace while $10.3 \%$ are exposed both at work and at home (table 1). The prevalence of passive smoking at work varies by occupation and by industry, from about $42 \%$ to $80 \%$ for men and $22 \%$ to $62 \%$ for women (table 2). The extent of non-smokers' exposure to secondhand smoke is significantly associated with the prevalence of smoking (Kendall's tau $=0.429, \mathrm{p}=0.033$ ), which ranges from $24 \%$ among males in administrative, managerial, and professional occupations to $49 \%$ among males in the construction industry. Exposure to passive smoking at work is associated with being younger, male, married, less educated, and having lower income levels (table 3). After controlling for possible confounding factors, those nonsmokers exposed to secondhand smoke in the workplace are $37 \%$ more likely (OR $=1.37,95 \%$ CI: 1.03 to 1.83 ) to visit a doctor for a cold, flu, or fever than those not exposed (table 4).

\begin{tabular}{|c|c|c|c|}
\hline & $\begin{array}{l}\% \text { exposed to smoke at } \\
\text { work }\end{array}$ & $\begin{array}{l}\% \text { exposed to smoke at } \\
\text { home }\end{array}$ & $\begin{array}{l}\% \text { exposed to smoke at } \\
\text { work and at home }\end{array}$ \\
\hline Males ( $n=1049$ ) & 56.6 & 18.5 & 9.2 \\
\hline Females $(n=912)$ & 36.7 & 34.3 & 11.6 \\
\hline Total $(n=1961)$ & 47.5 & 26.0 & 10.3 \\
\hline
\end{tabular}


Table 2 Unadjusted prevalence of passive smoking at work in full time, non-smoking workers, and of active smoking in all workers by type of occupation and industry

\begin{tabular}{|c|c|c|c|}
\hline & $\begin{array}{l}\mathrm{n} \text { in sample/n } \\
\text { non-smokers } \\
\text { in sample }\end{array}$ & $\begin{array}{l}\mathrm{n}(\%) \text { of all } \\
\text { workers who } \\
\text { smoke }\end{array}$ & $\begin{array}{l}n(\%) \text { non-smokers } \\
\text { exposed to smoke } \\
\text { at work }\end{array}$ \\
\hline \multicolumn{4}{|l|}{ Occupational categories } \\
\hline \multicolumn{4}{|l|}{ Males } \\
\hline Administrative, managerial, and professional & $496 / 337$ & $120(24.2)$ & $141(41.8)$ \\
\hline Clerks, service, and shop sales & $479 / 300$ & $151(31.5)$ & $181(60.3)$ \\
\hline Crafts, machine operators, and elementary occupations & $521 / 263$ & $245(47.0)$ & $190(72.2)$ \\
\hline Others & $82 / 44$ & $32(39.0)$ & $21(47.8)$ \\
\hline \multicolumn{4}{|l|}{ Females } \\
\hline Administrative, managerial, and professional & $239 / 206$ & $17(7.1)$ & $46(22.3)$ \\
\hline Clerks, service, and shop sales & $574 / 466$ & $42(7.3)$ & $193(41.4)$ \\
\hline Crafts, machine operators, and elementary occupations & $117 / 108$ & $5(4.3)$ & $43(39.8)$ \\
\hline Others & $26 / 19$ & $4(15.2)$ & $9(47.8)$ \\
\hline \multirow{2}{*}{\multicolumn{4}{|c|}{ Industry categories }} \\
\hline \multicolumn{3}{|l|}{ Males } & \\
\hline Manufacturing & $216 / 133$ & $68(31.5)$ & $81(60.9)$ \\
\hline Construction & $252 / 121$ & $122(48.5)$ & $97(80.1)$ \\
\hline Import/export, wholesale and retail, restaurants and hotels & $232 / 139$ & $74(31.9)$ & $81(58.2)$ \\
\hline Transport, communication & $250 / 152$ & $87(34.8)$ & 90 (59.4) \\
\hline Financing, business & $209 / 143$ & $63(30.1)$ & $62(43.4)$ \\
\hline Community, social services & $353 / 219$ & $113(32.0)$ & $105(48.0)$ \\
\hline Other & $61 / 38$ & $19(31.4)$ & $18(46.9)$ \\
\hline \multicolumn{4}{|l|}{ Females } \\
\hline Manufacturing & $148 / 129$ & $12(8.1)$ & $53(41.0)$ \\
\hline Construction & $15 / 15$ & 0 & $7(48.1)$ \\
\hline Import/export, wholesale and retail, restaurants and hotels & $231 / 192$ & $25(10.8)$ & $92(47.9)$ \\
\hline Transport, communication & $49 / 39$ & $3(6.1)$ & $24(62.0)$ \\
\hline Financing, business & $208 / 166$ & $15(7.2)$ & $53(31.9)$ \\
\hline Community, social services & $286 / 238$ & $10(3.5)$ & $57(24.0)$ \\
\hline Other & $28 / 19$ & $4(14.5)$ & $6(32.1)$ \\
\hline
\end{tabular}

Table 3 Characteristics of passive smoking full time workers

\begin{tabular}{|c|c|c|c|}
\hline & OR & $95 \% \mathrm{Cl}$ & $p$ value \\
\hline Age & 0.99 & 0.98 to 1.00 & 0.012 \\
\hline Male gender (baseline female) & 2.40 & 1.98 to 2.91 & $<0.001$ \\
\hline Married (baseline not married) & 1.24 & 1.00 to 1.54 & 0.046 \\
\hline Education to primary level (baseline tertiary level) & 3.07 & 2.06 to 4.57 & $<0.001$ \\
\hline $\begin{array}{l}\text { Per capita household income (US\$) \$0-769 } \\
\text { (baseline } \geqslant \$ 3206 \text { ) }\end{array}$ & 2.04 & 1.23 to 3.38 & 0.006 \\
\hline
\end{tabular}

Table 4 Adjusted ORs for having a consultation in the past 14 days for cold, flu, or fever in non-smoking full time workers

\begin{tabular}{lllc}
\hline & OR & $95 \% \mathrm{Cl}$ & p value \\
\hline Age & 0.97 & 0.95 to 0.99 & 0.007 \\
Male gender & 0.90 & 0.66 to 1.22 & 0.480 \\
Married & 1.26 & 0.88 to 1.78 & 0.204 \\
Chronic disease & 1.69 & 1.15 to 2.49 & 0.008 \\
Poor health (baseline good health) & 2.15 & 1.59 to 2.90 & $<0.001$ \\
Passive smoking at home & 1.07 & 0.77 to 1.50 & 0.684 \\
Passive smoking at work & 1.37 & 1.03 to 1.83 & 0.031 \\
1 smoker & 0.93 & 0.49 to 1.76 & P for trend is \\
2 smokers & 2.21 & 1.40 to 3.47 & 0.047 \\
3 or more & 1.27 & 0.91 to 1.77 & \\
\hline
\end{tabular}

As well as the above variables, the final model included level of income (five groups), type of medical benefits (four groups), occupation (six groups), and whether respondent lives alone.

In separate models (not shown) using the same covariates, the OR for any visit to a doctor was 1.09 (95\% CI: 0.85 to 1.40 ), and for a visit for any reason excluding preventive care was 1.04 (95\% CI: 0.80 to 1.35). The OR for a visit because of bronchitis was 2.6 (95\% CI: 0.18 to 36.46 ), but there were only 36 visits for this reason.
Almost half of the respondents (45.1\%) have no medical benefits and pay for medical care out of their own pockets, while $24.3 \%$ have benefits from their employer, $22.1 \%$ have private insurance, and $8.4 \%$ have government benefits because they are civil servants. Of those who made a visit to a doctor for a cold, flu, or fever in the previous 14 days, most (74.0\%) 
Table 5 Estimated number of extra consultations and cost of these consultations (US\$) in one year for the sample using the estimate of the OR and upper and lower bounds based on $95 \% \mathrm{Cl}$

\begin{tabular}{lccc}
\hline & OR=1.37 & $\begin{array}{c}\text { Lower } \\
\text { OR=1.03 }\end{array}$ & $\begin{array}{c}\text { Upper } \\
\text { OR=1.83 }\end{array}$ \\
\hline Estimated number of extra consultations & 1347 & 127 & 2543 \\
Estimated total cost of extra consultations & 29044 & 2745 & 54809 \\
Cost (\% of total) paid by government & $2444(8.4)$ & $228(8.3)$ & $4701(8.6)$ \\
Cost (\% of total) paid by employer & $8279(28.5)$ & $782(28.5)$ & $15610(28.5)$ \\
Cost (\% of total) paid by individual or insurer & $18322(63.1)$ & $1735(63.2)$ & $34498(62.9)$ \\
\hline
\end{tabular}

attended a private doctor. Those who attended a public clinic paid an average of $\$ 3.0$ as a co-payment and those attending a private doctor paid an average of \$23.3; of those who have employer medical benefits, $37.6 \%$ could claim the whole cost of the private consultation back and $50.7 \%$ could claim some of it. Using this data and the OR for consultations among passive smokers, we calculated both the number and cost of extra visits. Table 5 shows the total amounts paid and the payers who foot the bills.

If extrapolated to all of the 3.04 million full time workers in Hong Kong, we would have around 1.5 million extra visits at a cost to the government of around \$2.7 million (\$0.3-5.2 million), to employers of $\$ 9.1$ million (\$0.9-17.1 million), and to individuals themselves of \$20.1 million (\$1.9-37.8 million).

\section{DISCUSSION}

This survey is the first to examine the potential costs of exposure to secondhand smoke in a defined well population in the Asia Pacific region. It provides new evidence that passive smoking at work is an important component of the net economic loss sustained by all communities as a result of tobacco use. One limitation in extrapolating the results of this survey to the whole population in Hong Kong is that we cannot rule out the possibility of bias in the findings because of the relatively low response rate. However, validity checks did not find great differences between responders and nonresponders. A second limitation is the use of cross sectional data and therefore the interpretation of associations, and possible causal relations between the variables of interest, should be cautious. The third limitation is the use of self reported data.

To take the second limitation, consistency with other studies supports the hypothesis of a causal link. The OR found here (1.37) for the association of a visit to a doctor and exposure to secondhand smoke at work is very similar to that found in an independent study (1.36), for males exposed to secondhand smoke at work for more than one year in a single occupational group in Hong Kong, but slightly lower than the OR for the association with the use of medications for respiratory problems in that study $(1.53-1.79) .{ }^{12}$ The previous studies were in only one occupational group, while this study covers all occupations with a variety of levels of exposure to secondhand smoke. The evidence is therefore persuasive that some, if not all, of this association is caused by exposure to secondhand smoke, which means that the impact should be potentially avoidable.

In respect of the third limitation, the respondents to the survey were given no indication as to the hypotheses under investigation; most of the questionnaire focused on information about medical benefits, which was complicated data to collect. Therefore no recall bias should have been introduced but, if it does exists, it would tend to overestimate the effect of passive smoking. There could be some inflation in the absolute number of people who reported a visit to a doctor within the 14 day period if some respondents included visits made just outside that period. Any such systematic error should not affect the estimated OR, but might increase the estimate of the potential number of visits which could be saved. Another issue is the "survivor effect", where only people who are less affected by a smoky environment are willing to remain in that employment. If this effect exists here, it would cause an underestimation of the association between passive smoking and doctor visits.

As the ORs for all visits to a doctor and all visits excluding preventive care show, we only found an effect for what are probably principally upper respiratory problems (colds, flu, and fever). It would be of interest to examine, in a larger study, any impact on other conditions which might be associated with passive smoking, such as ear conditions and allergies.

We found that those most exposed to secondhand smoke at work are, as in Western societies, principally the younger and lower paid workers; a demonstration of inequitable working environments. These workers are also less able to pay for care, heightening the inequity associated with involuntary passive smoking. Whitlock et al showed that exposure to secondhand smoke was inversely associated with socioeconomic status in New Zealand, particularly in younger persons, men, and Maoris rather than European workers. ${ }^{17}$ Our study confirms these results and the conclusion that tobacco control should be targeted at these groups.

It is of interest to note that, in this population, the exposure to, and hence the impact of, passive smoking at work is greater than that at home.

This study lends further weight to the argument that allowing smoking in the workplace is costly to employers. This is the first study to apportion components of this cost to the various payers for care in this population. In other medical care systems, both the distribution of costs and their magnitude may differ from this case; nonetheless this case study highlights several points which are transferable to other systems. There is a significant cost to pay in ill health if nonsmokers are exposed to secondhand smoke in the workplace; this results in financial loss, perhaps principally to the workers themselves, but also, to varying degrees, to their employers, depending on health care arrangements. In the case of Hong Kong, the employers are paying more than the government, but even the relatively small amount paid by the government could be better spent; for example, in an exercise to educate workers and employers about the risks of passive smoking or to assist employers in enforcement of nonsmoking policies.

\section{ACKNOWLEDGEMENTS}

The survey on which these analyses is based was carried out in collaboration with the School of Public Health, Harvard University; in particular, Dr Winnie Yip of Harvard University and Dr John Bacon-Shone of the University of Hong Kong helped to design the questionnaires and collect the data. Ms LC Wong and Ms Sharon Luk carried out the statistical analyses. Professor AJ Hedley is chairman of the Hong Kong Council on Smoking and Health. 


\section{Main messages}

- In a sample of workers in Hong Kong, passive smoking at work was more common than passive smoking at home.

- Passive smoking at work was associated with a $37 \%$ increase in visits to a doctor for cold, flu, or fever.

- These extra visits, when extrapolated to all full time workers in Hong Kong, cost a total of around US\$32 million (range US\$3-60 million).

\section{Policy implications}

- Extra health care use by non-smokers, and associated costs are potentially avoidable by eliminating exposure of non-smokers to secondhand smoke at work.

- Costs of setting up and enforcing non-smoking policies at work are potentially recoverable in the short term through reduced health care use.

\section{Authors' affiliations}

S M McGhee, A J Hedley, L M Ho, Department of Community

Medicine, University of Hong Kong, 5th Floor, University of Hong Kong

Medical Centre, 21 Sassoon Road, Hong Kong

\section{REFERENCES}

1 US Department of Health and Human Services. Reducing tobacco use. A Report of the Surgeon General. Atlanta, GA: US Department of Health and Human Services, Centers for Disease Control and Prevention, National Center for Chronic Disease Prevention and Health Promotion, Office on Smoking and Health, 2000.

2 Wells AJ. Heart disease from passive smoking in the workplace. J Am Coll Cardiol 1998;31:1-9.
3 Corrao MA, Guindon GE, Sharma N, Shokoohi DF, eds. Tobacco control country profiles. Atlanta, GA: American Cancer Society, 2000

4 Hammond SK. Exposure of US workers to environmental tobacco smoke. Environ Health Perspect 1999;107:329-40.

5 Kauppinen T, Toikkanen J, Pedersen D, et al. Occupational exposure to carcinogens in the European Union. Occup Environ Med 2000;57:10-18.

6 Pirkle JL, Flegal KM, Bernert JT, et al. Exposure of the US population to environmental tobacco smoke: the Third National Health and Nutrition Examination Survey, 1988-1991. JAMA 1996;275:1233-40.

7 National Center for Health Statistics. Vital and health statistics: current estimates from the National Health Interview Survey, 1988. DHHS publication number (PHS) 89-1501. Hyattsville, MD: US Department of Health and Human Services, Public Health Service, Centers for Disease Control, National Center for Health Statistics, 1989.

8 Patten CA, Gilpin E, Cavin SW, et al. Workplace smoking policy and changes in smoking behavior in California: a suggested association. Tob Control 1995;4:36-41.

9 Western Pacific Regional Office, World Health Organisation. Country profiles on tobacco or health. Geneva: WHO, 2000.

10 Lam TH, Ho LM, Hedley AJ, et al. Environmental tobacco smoke exposure among police officers in Hong Kong. JAMA 2000;284:756-63.

11 Kristein MM. How much can business expect to profit from smoking cessation? Prev Med 1983;12:358-81.

12 McGhee SM, Adab P, Hedley AJ, et al. Passive smoking at work: the short-term cost. J Epidemiol Community Health 2000;54:673-6.

13 White JR, Froeb HF, Kulik JA. Respiratory illness in nonsmokers chronically exposed to tobacco smoke in the workplace. Chest 1991;1:39-43.

14 Mannino DM, Siegel M, Rose D, et al. Environmental tobacco smoke exposure in the home and worksite and health effects in adults: results from the 1991 National Health Interview Survey. Tob Control 1997:6:296-305.

15 Environmental Protection Agency. The costs and benefits of smoking restrictions. An assessment of the Smoke-Free Environment Act of 1993. Washington, DC: Office of Radiation and Indoor Air, 1994

16 Census \& Statistics Department, Hong Kong. 1996 population by-census. Hong Kong: Census and Statistics Department, 1996.

17 Whitlock G, MacMahon S, Vander Hoorn S, et al. Association of environmental tobacco smoke exposure with socioeconomic status in a population of 7725 New Zealanders. Tob Control 1998;7:276-80.

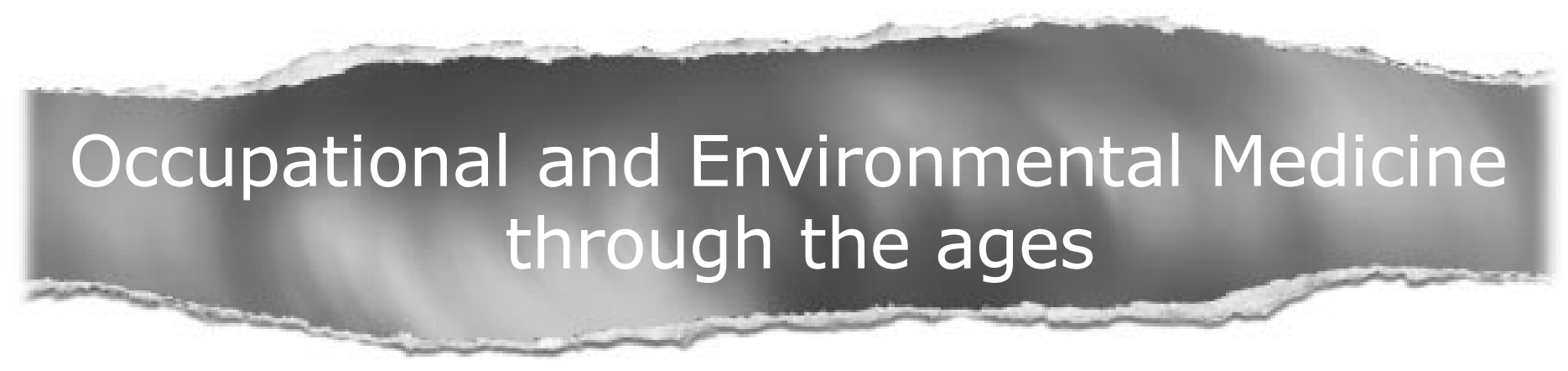

Browse the Archive

Occupational and Environmental Medicine online has an archive of content dating back to 1994.

Full text from January 2000; abstracts from 1998; table of contents from 1994

www.occenvmed.com 